\title{
REVISÃO SISTEMÁTICA SOBRE LINGUAGEM NAS PRODUÇÕES CIENTÍFICAS DA PÓS-GRADUAÇ̃̃̃O EM EDUCAÇÃO E ENSINO NA REGIÃ̃O AMAZÔNICA
}

\section{SYSTEMATIC REVIEW ABOUT LANGUAGE IN SCIENTIFIC PRODUCTIONS OF POSTGRADUATE IN EDUCATION AND TEACHING IN THE AMAZON REGION}

Evandro Luiz Ghedin ${ }^{1}$

ORCID iD: 0000-0002-2844-6122

Maria Leogete Joca da Costa ${ }^{2}$

ORCID iD: 0000-0002-4485-3561

Patrik Marques dos Santos ${ }^{3}$

ORCID iD: 0000-0001-5105-4891

\begin{abstract}
RESUMO
Este trabalho teve como foco principal a realização de um levantamento das teses e dissertações no Banco de Teses da Coordenação de Aperfeiçoamento de Pessoal de Nível Superior - Capes, para composição de uma Revisão Sistemática (RS) sobre o estudo da linguagem nos programas de pósgraduação em educação e ensino na região Amazônica. A pesquisa sustentou-se nos seguintes objetivos: Conhecer as teses e dissertações produzidas nos programas de pós-graduação em educação e ensino da região Amazônica sobre a linguagem; apresentar o percurso metodológico e as bases teóricas das teses e dissertações sobre a linguagem no período de 2013 a 2018; e analisar as produções científicas que abordaram a Linguagem além de identificar as categorias, sua função e sua contribuição para a educação e o ensino. Os resultados apontaram produções em linguagem matemática e científica, processo cognitivo e linguagem oral e escrita, sendo mais evidenciados nas produções científicas analisadas, e uma limitada produção científica sobre a linguagem na região Amazônica.
\end{abstract}

Palavras-chave: Linguagem. Ensino. Educação. Programas de Pós-Graduação. Região Amazônica.

\begin{abstract}
This work had as main focus the accomplishment of a survey of theses and dissertations in the Thesis Bank of the Coordination of Improvement of Higher Education Personnel - Capes - to compose a Systematic Review (RS) on the study of language in postgraduate programs in education. and education,

\footnotetext{
${ }^{1}$ Pós-doutorado em Didática pela Universidade de São Paulo (USP). Doutor em Filosofia da Educação pela Universidade de São Paulo (USP). Mestrado em Educação pela Universidade Federal do Amazonas. Professor Titular-Livre da Faculdade de Educação da Universidade Federal do Amazonas (UFAM), Manaus, Amazonas, Brasil. Endereço para correspondência: Av. Comendador José Cruz, n. 515 - Bl 09 Apto 304 - CD T Ville Liberdade - Lago Azul - Manaus, Amazonas, Brasil, CEP: 69.018-150 - E-mail: evandroghedin@ufam.edu.br.

${ }^{2}$ Discente de curso de Doutorado em Educação e Mestrado em Educação pelo Programa de Pós-graduação em Educação da Universidade Federal do Amazonas - UFAM. Professora da Universidade Federal de Roraima UFRR. Endereço para correspondência: Rua: Antônio Pinheiro Filho, 1431, Caranã, Boa Vista, Roraima, Brasil, CEP: 69.313-585. E-mail: maria.leogete@ufrr.br.

${ }^{3}$ Discente de curso de Doutorado em Educação em Ciências e Matemática da Universidade Federal do Mato Grosso (UFMT) - REAMEC, Polo UEA/Manaus e Mestrado em Educação em Ensino de Ciências pela Universidade do Estado do Amazonas (UEA). Professor do Instituto Federal de Educação, Ciência e Tecnologia do Amazonas (IFAM), Parintins, Amazonas, Brasil. Endereço para correspondência: Rua: Dom Gino Malvestio, 3658, Paulo Corrêa, Parintins, Amazonas, CEP: 69.152-033. E-mail: patrik.santos@ifam.edu.br.
} 
from the Amazon region. The research was based on the following objectives: know theses and dissertations produced in postgraduate programs in education and teaching in the Amazon region on language; to present the methodological path and the theoretical basis of theses and dissertations about language in the period from 2013 to 2018; and to analyze the scientific productions that approached the Language besides identifying the categories, their function and their contribution to education and teaching. The results indicated productions in mathematical and scientific language, cognitive process and oral and written language, being more evidenced in the analyzed scientific productions, and a limited scientific production about the language in the Amazon region.

Keywords/Palabras clave: Language. Teaching. Education. Postgraduate Programs. Amazon Region.

\section{INTRODUÇÃO}

Este trabalho, com natureza de investigação científica, foi estruturado a partir do objetivo geral de realizar um levantamento das teses e dissertações, no Banco de dados da Capes $^{4}$, para composição de uma revisão sistemática sobre o estudo da linguagem nos programas de pós-graduação em educação e ensino, na região Amazônica, norteado pela seguinte questão investigativa: Como a linguagem é discutida nas teses e dissertações dos programas de pós-graduação, em educação e ensino, da região Amazônica?

Para atender à proposição em evidência, três objetivos específicos foram gerenciadores deste estudo, a saber: Conhecer teses e dissertações produzidas nos programas de pósgraduação,, em educação e ensino, da região amazônica sobre a linguagem; apresentar o percurso metodológico e a bases teóricas das teses e dissertações sobre a linguagem no período de 2013 a 2018; e analisar as produções científicas que abordaram a Linguagem além de identificar as categorias, sua função e sua contribuição para a educação e o ensino. Em consonância com os objetivos supracitados, o estudo foi operacionalizado no software StArt ${ }^{5}$ (State of the Art), com apoio do $W_{\text {ordle }}^{T M 6}$ para criação de nuvem de palavras nas sistematizações do conteúdo identificado.

A Revisão Sistemática (RS) é uma técnica utilizada para buscar evidências na literatura científica com aplicação de etapas bem definidas e gerenciadas por um protocolo, o qual direciona toda atividade, cuja execução é manual, trabalhosa e repetitiva, porém compensatória, possibilitando ao pesquisador uma melhor sistematização e organização de todas as informações coletadas.

\footnotetext{
${ }^{4}$ Endereço eletrônico: http://www.periodicos.capes.gov.br.

${ }^{5}$ StArt (Version 2.3.4.2), desenvolvido pelo Laboratório de pesquisa em engenharia de software da Universidade Federal de São Carlos no estado de São Paulo. Endereço eletrônico: http://lapes.dc.ufscar.br/tools/start tool.

${ }^{6}$ Endereço eletrônico: http://www.wordle.net.
} 
Já a nuvem de palavras, possui um mecanismo de sistematização de informação diferente da RS em que se agrupam palavras mais frequentes em textos e organiza-as como imagem. Sua contagem é por meio de um aglomerado de palavras diferenciam-nas pelos tamanhos e intensidades, o que se referem a quantidade de vezes que são citadas no texto, e que, para este trabalho, auxiliou como instrumento metodológico qualitativa na análise dos tópicos levantados pela RS.

O próprio software StArt já é semiestruturado, cabendo aos pesquisadores fazer o planejamento para preenchimento contemplando os mais diversos itens, sendo os principais: Questão ou Problema de pesquisa, Objetivos, a População, Resultado, Análise, Comentários, Classificação em Aceitar, Rejeitar e/ou Duplicado e os critérios de Inclusão e Exclusão.

Vale ressaltar que neste estudo foi utilizado vários critérios e strings de busca, ou seja, para selecionar os trabalhos, entre eles destacam-se a utilização do título, das palavras-chave e do resumo; para analisar e extrair o percurso metodológico e as bases teóricas dos trabalhos, utilizou-se o Resumo, a Introdução, a Fundamentação Teórica e Metodologia; e para encontrar o conceito de linguagem, além do Título e das Palavras-chave, recorreu-se ao Resumo, Introdução à Conclusão/Considerações Finais.

Em suma, o texto resultante desta RS estrutura-se com as seguintes subseções: A produção científica sobre a linguagem na região Amazônica; O percurso metodológico e as bases teóricas; e a Análise das produções científicas sobre Linguagem: categorias, função e contribuição para a educação e o ensino. É importante destacar que as subseções correspondem a cada objetivo específico planejado para construção do protocolo supracitado.

\section{A PRODUÇÃo CIENTÍFICA SOBRE A LINGUAGEM NA REGIÃo AMAZÔNICA}

O levantamento de dados e a Revisão Sistemática (RS) feitos sobre o tema "linguagem" constituiu um processo de análise qualitativa das pesquisas realizadas nos Programas de PósGraduação da região Amazônica nas mais diversas áreas do conhecimento no período de 2013 a 2018. A escolha desse marco temporal estava condicionada ao período em que a Capes começou a utilizar a tecnologia Elastic Search (ES) e Java em 2013, ou seja, em anos anteriores, havia muitos títulos de trabalhos mencionados, porém o arquivo da tese ou dissertação não estava disponível.

Para esta pesquisa, utilizou-se o software StArt, ferramenta estruturada na língua inglesa, organizada em três etapas denominadas: Planning, (elaboração do Protocolo, espaço reservado para se especificar: os objetivos, a questão norteadora, as palavras-chave, critérios de 
inclusão e exclusão, escolha de idioma e o classificador da busca). Seguido da Execution (espaço reservado para definição dos trabalhos aceitos ou rejeitados, e ainda duplicados, conforme critérios estabelecidos para o preenchimento do formulário do Protocolo); e Summarization (espaço reservado para geração e visualização de gráficos, redes e fluxogramas de todas as informações categorizadas, com a possibilidade de elaboração de planilhas).

E aqui se destaca que, mesmo a pesquisa limitada apenas a região amazônica, fez-se, primeiro, um levantamento, no Banco de dados da Capes, considerando todos os procedimentos criteriosos adotados a partir do que propõe o software StArt, como se descreverá a seguir: definição dos descritores ou strings para direcionar a busca a ser realizada com o string individual "linguagem" para se ter um panorama geral de todas as Dissertações e Teses da Capes, do qual se obteve um total de 53.170 trabalhos produzidos em todas as regiões, sendo 11.611 Teses e 41.560 Dissertações, dos quais 38.501 são de mestrados acadêmicos e 3.059 de mestrados profissionais.

Ainda usando string individual "linguagem", mas com o filtro por ano, compreendendo o período de 2013 a 2018, encontrou-se 23.521 trabalhos, distribuído na seguinte ordem: 15.299 dissertações de mestrados acadêmico e 2.571 profissional e 5.561 teses. E usando a mesma string, mas com o filtro por Área do Conhecimento: Educação e Ensino, foram encontrados, em todas as regiões, 2.243 Dissertações de mestrado acadêmico; 464, profissionais e 814 Teses, totalizando 3.521 trabalhos produzidos no período mencionado. A utilização dos filtros por ano e por área de conhecimento: Educação e Ensino foram critérios estabelecidos para facilitar a busca no site.

E para cumprir o proposto por um dos objetivos específicos que era o de sistematizar teses e dissertações produzidas nos programas de pós-graduação, em educação e ensino, da Região Amazônica sobre a linguagem, o protocolo para armazenar, no software StArt, todas as informações que se pretendia obter para a construção deste artigo, foi seguido. E com a utilização da string individual "linguagem", foi detectado os seguintes trabalhos conforme demonstração no Quadro 1, a seguir:

\begin{tabular}{|c|c|c|}
\hline Programas de Pós-graduações & \multirow{2}{*}{ N. $^{\circ}$ de trabalhos } & \multirow{2}{*}{ Total } \\
\hline Dissertação Mestrado acadêmico & 137 & \multirow{2}{*}{206} \\
\hline Dissertação Mestrado Profissional & 36 & \\
\hline Teses & 33 \\
\hline
\end{tabular}

Quadro 1 - Trabalhos selecionados na string linguagem na Região Amazônica Fonte: Produção dos autores (2019)

A pesquisa foi realizada também com busca associada de 2 a 4 termos, com a utilização de vários filtros, tais como: Educação e Ensino; Região Amazônica; e por ano como se verifica 
nos quadros 2 e 3, respectivamente, Descritores e quantitativo de trabalhos no cenário nacional e na região Amazônica / Termos associados e o filtro de busca.

\begin{tabular}{|c|c|c|c|}
\hline \multicolumn{4}{|c|}{ Descritores e quantitativo de trabalhos no cenário nacional e na região Amazônica } \\
\hline Descritores/Strings & $\begin{array}{l}\text { Nacional } \\
(2013 \text { a } 2018)\end{array}$ & $\begin{array}{l}\text { Região Amazônica } \\
\text { (2013 a 2018) }\end{array}$ & Data da busca \\
\hline Linguagem & 53.170 & 206 & 05/03/2019 \\
\hline Linguagem e ensino & 1.143 .933 & 2.722 & 05 e $06 / 03 / 2019$ \\
\hline Linguagem e educação & 1.144 .112 & 2.722 & 09 e $10 / 03 / 2019$ \\
\hline Linguagem e Região amazônica & 1.143 .934 & 2.571 & 09 e $10 / 03 / 2019$ \\
\hline Linguagem, educação e ensino & 1.144 .134 & 2.571 & 13 e $14 / 03 / 2019$ \\
\hline $\begin{array}{c}\text { Linguagem, educação, ensino e região } \\
\text { amazônica }\end{array}$ & 1.144 .195 & 2.571 & 15 a $18 / 03 / 2019$ \\
\hline
\end{tabular}

Quadro 2 - Relação de strings de busca na região Amazônica Fonte: elaborado pelos autores (2019)

\begin{tabular}{|c|c|}
\hline \multicolumn{1}{|c|}{$\begin{array}{c}\text { Termos associados e filtro de busca } \\
\text { Busca associada por termos }\end{array}$} & Critério de refinação de busca \\
\hline 1. Linguagem & Sem filtro \\
\hline 2. Linguagem e ensino & Por ano 2013 a 2018 \\
3. Linguagem e educação & Educação e ensino \\
\hline 4. Linguagem e Região amazônica & Região amazônica \\
\hline 5. Linguagem, educação e ensino & 6. Linguagem, educação, ensino e região amazônica
\end{tabular}

Quadro 3 - Critérios de refinação de busca às produções científicas Fonte: elaborado pelos autores

Em conformidade com o registro no Protocolo inicial do StArt, a escolha dos termos de busca associada e os critérios de refinação de busca ocorreu a partir da questão norteadora "Como a linguagem é discutida nas teses e dissertações dos programas de pós-graduação, em educação e ensino, da região Amazônica?", tal questão também direcionou mais um critério para busca no banco de dados, que foi a utilização das palavras-chave, resumos e identificação dos títulos das dissertações e teses.

Com os descritores de busca apresentados no Quadro 2 e os critérios de refinação do Quadro 3, é possível registrar o quantitativo de trabalhos encontrados na região Amazônica, conforme demonstrado na Tabela 1. 


\begin{tabular}{c|c|c|c|c|c}
\multicolumn{7}{c}{ Tabela 1 - Quantitativo de buscas por descritores } \\
\hline & $\begin{array}{c}\text { Linguagem } \\
\text { e ensino }\end{array}$ & $\begin{array}{c}\text { Linguagem } \\
\text { e educação }\end{array}$ & $\begin{array}{c}\text { Linguagem } \\
\text { e região } \\
\text { amazônica }\end{array}$ & $\begin{array}{c}\text { Linguagem, } \\
\text { educação } \\
\text { e ensino }\end{array}$ & $\begin{array}{c}\text { Linguagem, } \\
\text { educação, ensino } \\
\text { e Região } \\
\text { Amazônica }\end{array}$ \\
\hline Sem filtro & 1.143 .933 & 1.144 .112 & 1.143 .924 & 1.144 .134 & 1.144 .195 \\
\hline Por ano 2013 a 2018 & 471.215 & 471.246 & 471.211 & 471.253 & 471.265 \\
\hline Educação e ensino & 38.826 & 38.829 & 38.798 & 38.832 & 38.832 \\
\hline Região amazônica & 2.722 & 2.722 & 2.571 & 2.571 & 2.571 \\
\hline \multicolumn{5}{c}{ Fonte: elaborado pelos autores } \\
\hline
\end{tabular}

Sabe-se que compor um Estado da Arte por meio de uma RS não significa limitar-se apenas a identificação dos trabalhos produzidos, é ir além disso, como se pode comprovar nas palavras de Romanowski e Ens (2006) ao afirmarem que "esses trabalhos não se restringem a identificar a produção, mas analisá-la, categorizá-la e revelar os múltiplos enfoques e perspectivas.” As autoras fundamentadas em Soares (1989) acrescentam que:

esses estudos são necessários "no processo de evolução da ciência, a fim de que se ordene periodicamente o conjunto de informações e resultados já obtidos, favorecendo a organização que mostre a integração e a configuração emergentes, as diferentes perspectivas investigadas, os estudos recorrentes, às lacunas e as contradições (ROMANOWSKI ; ENS, 2006, p. 40).

Após percorrer todos passos descritos no Planning, objetivando atingir a Execution foram realizadas as seguintes ações: Selecionar dissertações e teses, além de baixar o arquivo no formato PDF, em cujos títulos o string linguagem comparecesse para composição de quadro com as seguintes informações: Título, nome do autor, nome do orientador, classificação do nível do estudo: dissertação (Mestrado acadêmico e profissional) e tese, IES, palavras-chave e ano.

Seguida de leitura dos resumos para o exercício da categorização e identificação dos trabalhos, de acordo com os critérios de inclusão e exclusão, a saber: Inclusão (I): Produção dos Programas de Pós-graduação em Educação e ensino na Região Amazônica; Produção realizada nos últimos 6 anos - de 2013 a 2018; Estudo sobre a linguagem; Constar a palavra linguagem nas palavras-chave ou título ou resumo; Trabalhos teóricos e experimentais sobre linguagem; Disponível na Plataforma Sucupira em formato digital; Exclusão (E): Não apresenta um estudo da linguagem, apenas utilizar o termo no resumo; Não apresenta um estudo da linguagem, apenas utilizar o termo nas palavras-chave.

Obedecendo a esse percurso, foi possível, dos 206 trabalhos encontrados na região amazônica, selecionar 63, analisar 44 e rejeitar 19, os quais passaram pelo processo mencionado no protocolo, de classificação e enquadramento no perfil denominado Accepted Papers, 
(Aceitar) Rejected Papers (Rejeitar) Duplicated Papers (Duplicidade) e até Unclassified Papers (Não classificar) como se pode observar na Figura 1.

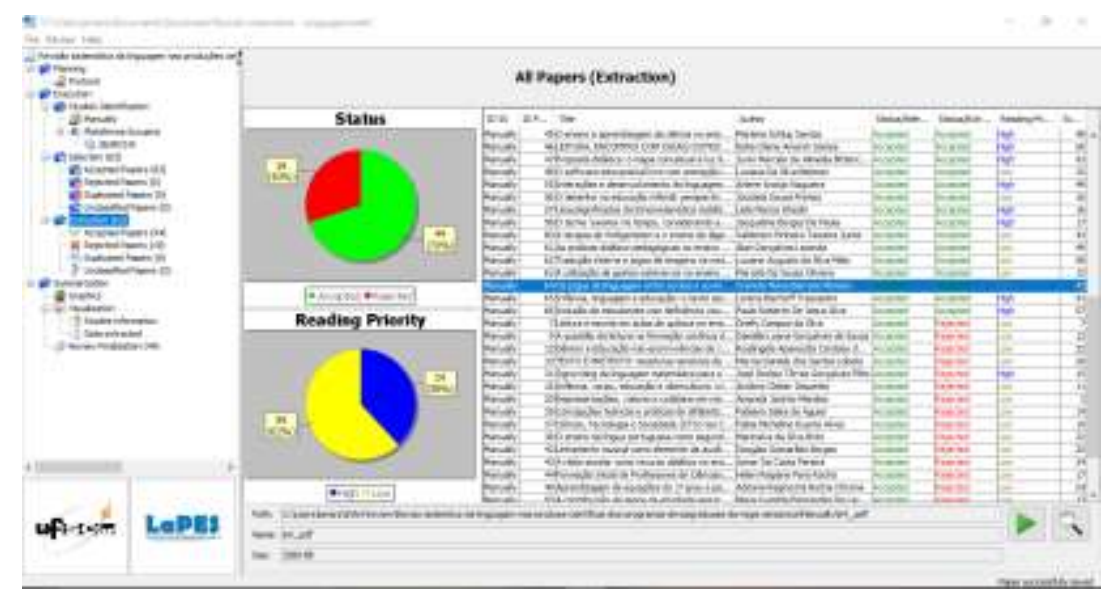

Figura 1 - Tela do software StArt com total de trabalhos aceitos e rejeitados Fonte: elaborado pelos autores.

No gráfico 1, a seguir, apresenta-se o quantitativo de teses e dissertações encontradas, no Banco de dados da Capes, com identificação do termo linguagem, especificamente, nos programas de pós-graduação em educação e ensino na região amazônica e a quantidade referente aos aceitos, rejeitados, duplicados e os selecionados para análise.

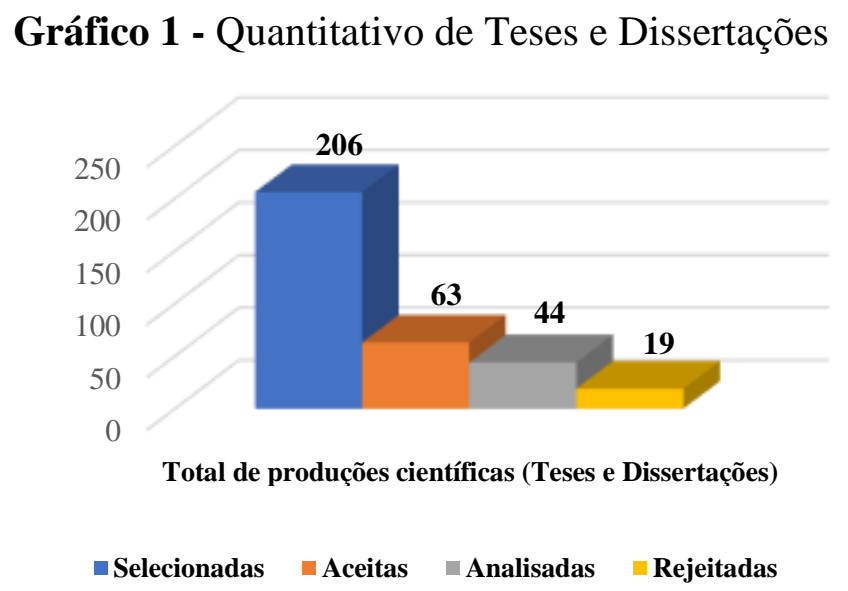

Fonte: elaborado pelos autores.

Destaca-se que os 19 trabalhos foram rejeitados por apresentar o termo linguagem apenas no Título e Palavras-chave, não comparecendo no Resumo, Introdução e Conclusão/Considerações Finais, totalizando 1 tese e 18 dissertações.

Expressa o quantitativo das produções científicas selecionadas, a Revisão Sistemática segue seu percurso, em cumprimento ao segundo objetivo planejado que era o de apresentar o 
percurso metodológico e as bases teóricas das teses e dissertações sobre a linguagem no período de 2013 a 2018.

\section{APORTE TEÓRICO E METODOLÓGICO SOBRE A LINGUAGEM NA EDUCAÇÃO E NO ENSINO}

O percurso metodológico evidenciado nos 44 trabalhos analisados compõe um ponto elucidador a futuros pesquisadores que pretendem buscar maior compreensão sobre a linguagem no cenário Amazônico, além de poder contribuir sobre as vertentes teóricas assumidas por muitas das produções científicas compiladas a respeito da temática. As peculiaridades de olhares e aproximações dos pesquisadores sobre a temática tecem novas perspectivas e instigam a conhecer as experiências no delineamento teórico-metodológico das produções científicas dessa temática, um desafio muito grande dentro da especificidade desta região.

Assim, nesta seção, consubstancia o pretendido em um dos objetivos da pesquisa, em apresentar a natureza teórica e metodológica das teses e dissertações sobre a linguagem no período de 2013 a 2018 na Pós-graduação em Educação e Ensino.

As teses e dissertações claramente traçam um paradigma qualitativo na abordagem metodológica, até mesmo àquelas não definidas (38\%), com exceção de dois trabalhos quantiquali sobre cartografia e dialetologia ${ }^{7}$ (ALVES, 2013; SÁ, 2013). Entretanto, a natureza da pesquisa, percebida em alguns trabalhos, justifica uma forma singular e emancipadora onde se finca no paradigma qualitativo a conjuntura de desenhar a pesquisa agregando técnicas e instrumentos conhecidos. Não assumem vínculos claros com qualquer tipo de pesquisa conhecida nas abordagens qualitativas, o que justifica a intensidade do termo "qualitativo" como destaca na nuvem de palavras da Figura 2, ou seja, a pesquisa qualitativa tornou-se um viés modelável às pesquisas.

Também na Figura 2, demonstra a emersão realçada quanto ao tipo de pesquisa assumida, mesclando-as e possibilitando novas abordagens de aproximação ao objeto, como pesquisas bibliográficas $\left(n^{8}=8\right)$, documentais $(n=5)$, pesquisa-ação $(n=4)$, etnográficas $(n=$ $4)$, pesquisas de campo $(n=2)$, quanti-quali $(n=2)$, dialetologias $(n=2)$, entre outras. Por outro

\footnotetext{
${ }^{7}$ A Dialetologia como ciência maior abarca a geolinguística como método que tem por finalidade identificar, descrever e situar os diferentes usos, mostrando eficácia para o conhecimento das variantes de uma língua. Perante ao pressuposto, a idade, o gênero, a escolaridade e características gerais de cunho sociocultural dos usuários das línguas, tornam elementos de investigação, em que há confluências de objetivos entre a dialetologia e a sociolinguística no que se refere à busca constante de variações (ALVES, 2013, p. 37).
}

$8 \mathrm{n}$ = número de vezes que comparece a palavra na compilação dos dados para a Nuvem de Palavras. 
lado, algumas delas podem não ter definido com exatidão o modelo de pesquisa conhecido pela própria complexidade em observar, analisar e interpretar os dados, mas "que todas elas podem ser caracterizadas por traços comuns" (TRIVIÑOS, 1987, p, 120), como de natureza qualitativa $(\mathrm{n}=33)$.

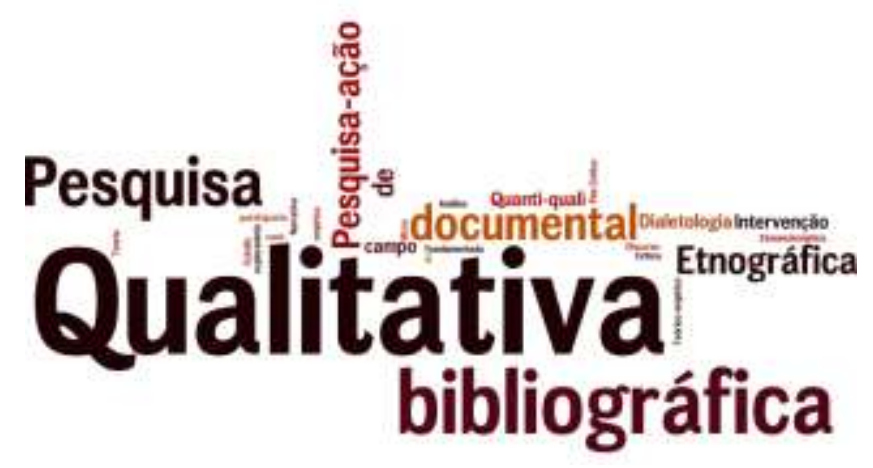

Figura 2 - Natureza e tipo de pesquisa Fonte: elaboração dos autores.

Na Nuvem de Palavras, gerada pelos pesquisadores no Wordle ${ }^{T M}$, representada na Figura 3, compilou-se as técnicas de coleta de dados mais utilizadas nas produções, percebendo conjuntos de técnicas e instrumentos, como as observações (18), observações participantes (n $=7)$ e entrevistas $(n=18)$ semiestruturadas $(n=7)$, não deixando de perceber a presença da análise de documentos $(\mathrm{n}=10)$. Também, atentou-se o questionário semiestruturado $(\mathrm{n}=7)$, audiovisual $(\mathrm{n}=5)$ e diário de campo $(\mathrm{n}=5)$ compondo instrumentos mais aplicados às pesquisas.

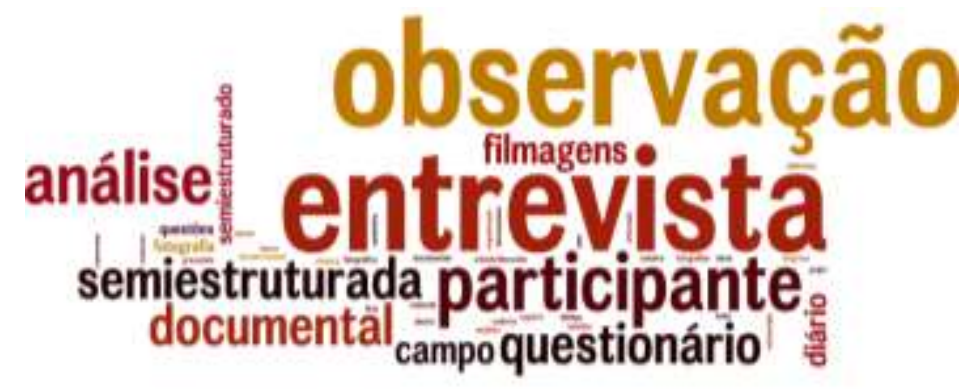

Figura 3 - Técnicas e instrumentos mais utilizados nas produções levantadas Fonte: elaboração dos autores.

As produções se preocuparam no detalhamento dos fatos e utilizaram mais de uma técnica e/ou instrumento na pesquisa, onde implicou em muitos dados subjetivos e requerente de uma atenção refinada, treinada, para interpretações e análises dos dados, tornando-as uma apresentação de dados muito cuidadosa e profunda do fenômeno. Tais dados carregam particularidades e estreitamento nas relações do sujeito com outros sujeitos ou objetos e o 
entendimento do próprio sujeito, e precisariam ser mais bem detalhados nos procedimentos metodológicos da pesquisa.

Em se tratando de pressupostos metodológicos e epistemológicos de pesquisa, indagações inúmeras surgem, entre tantas outras exemplifica-se: Quais as barreiras metodológicas da pesquisa impedem de debruçar com intimidade a complexidade da pesquisa? Que sustentação teórico-metodológica fundamenta o problema científico? Quais caminhos metodológicos e epistemológicos atendem os objetivos pretendidos na pesquisa?

O que se quer dizer com os exemplos mencionados, é que mesmo que se tenha uma armação perfeitamente funcional, em uma pesquisa, necessitará ter uma lente adequada e precisa para entender qual escala se pretende chegar, que relações observar e como proceder caso haja alterações no percurso. Nesse caso, necessita, além de tudo, assumir o construto teórico e epistemológico que melhor elucidará os fatos em questão, respeitando todo o processo ontológico de seu estudo (GONZÁLEZ REY, 2015).

Abarcar o estudo da linguagem no contexto da educação e do ensino cada vez mais indicia novas lacunas de exploração dentro das limitações das áreas, e é pertinente clarificar o rigor científico na descrição no percurso metodológico, mas também a corrente filosófica, epistemológica e as bases teóricas que ancoram a produção científica; visto que uma pequena parte não destaca claramente no decurso representado posteriormente no quadro 4.

Além disso, percebeu-se que algumas dissertações compuseram seus alicerces teóricos na ressignificação de produções científicas, deixando de explorar o cerne da discussão da construção do conhecimento de teóricos da linguagem em suas próprias obras, até mesmo teóricos e autores contemporâneos, por, quem sabe, limitações de idioma, dificuldade de acesso às obras ou linguagem utilizada pelo teórico.

Em contrapartida, a representatividade teórica e de autores da linguagem presentes das obras emergiram nas fundamentações dos trabalhos; outros, na análise e interpretação dos dados, encorpando uma discussão teórico aos profundos estudos dos teóricos da linguagem.

Na Figura 4, destaca-se os teóricos Vigotsky $(n=14)$, Bakhtin $(n=12)$ e Wittgenstein $(n=10)$ como mais citados no corpus das produções científicas. É importante realçar outros autores identificados, como Saussure $(n=6)$, Luria $(n=5)$, Leontiev $(n=4)$, Geraldi $(n=4)$, Chomsky ( $n=3)$ e Gottschalk $(n=3)$, importantes teóricos no estudo da linguagem. 


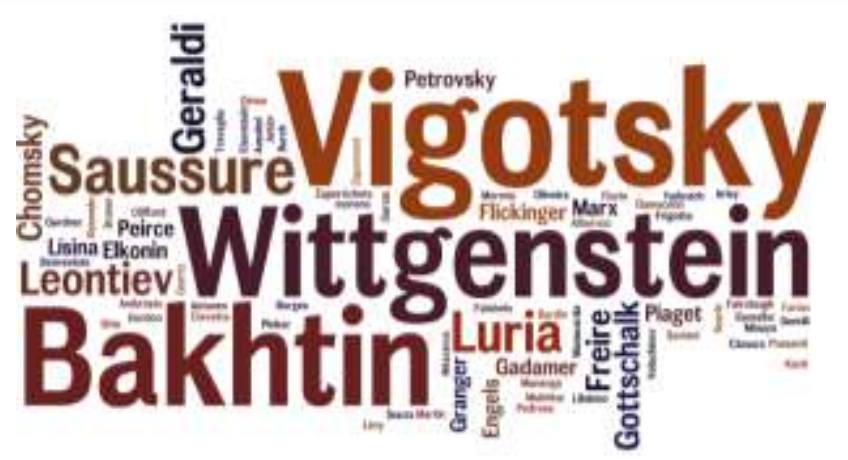

Figura 4 - Bases teóricas e autores identificados nas produções Fonte: elaboração dos autores.

Logo, neste panorama, depara-se com sustentações teóricas elencadas nos pressupostos Histórico-cultural, Sociointeracionismo, Jogos de Linguagem, Sociolinguística, Materialismo Dialético e Hermenêutica nas produções o que endossam as discussões sobre o entendimento da linguagem. Além das bases teóricas citadas, as teorias da Linguagem Cinematográfica, Aprendizagem Dialógica, Teoria Otteana, Teoria das Inteligências Múltiplas e Teoria da Aprendizagem Significativa aparecem nas teses e dissertações sistematizadas. Todavia, 18\% dos trabalhos não expuseram com clareza suas bases teórico-metodológicas, onde se condensou no quadro 4.

\begin{tabular}{|c|c|c|c|c|c|c|c|}
\hline Teorias & 2013 & 2014 & 2015 & 2016 & 2017 & 2018 & Total \\
\hline Histórico-cultural & 1 & - & 2 & 2 & 1 & 2 & \multirow{8}{*}{44} \\
\hline Sociointeracionismo & 1 & - & - & 1 & 1 & 2 & \\
\hline Jogos de Linguagem & 1 & - & 2 & 1 & 2 & 4 & \\
\hline Sociolinguística & 2 & - & - & 2 & - & - & \\
\hline Materialismo dialético & 1 & - & 1 & - & - & - & \\
\hline Hermenêutica & 1 & - & - & - & - & 1 & \\
\hline Outros & - & 1 & 1 & 1 & 1 & 1 & \\
\hline Não apresentou com clareza & 1 & - & 1 & 2 & 1 & 3 & \\
\hline
\end{tabular}

Nas 44 produções científicas aceitas na RS, a partir dos critérios tomados, o que se observou, no geral, foi um número pequeno de dissertações com composições bem definidas metodologicamente, com fundamentações teórico-epistemológicas rasas sobre a linguagem, claramente retraídas em assumir uma postura teórica sobre a discussão, preocupando-se em apenas demonstrar a análise dos resultados de forma crítica, pessoal e sem uma perspectiva teórica embasada. Muitas expuseram a temática em seus títulos e palavras-chave, porém não se tratava de uma pesquisa sobre linguagem, mas de algo que chamavam assim - o que será discutido na seção seguinte. 


\section{ANÁLISE DAS PRODUÇÕES CIENTÍFICAS SOBRE LINGUAGEM: CATEGORIAS, FUNÇÃO E CONTRIBUIÇÃO PARA A EDUCAÇÃO E O ENSINO}

Os trabalhos aceitos e analisados neste estudo, apontaram contribuições ao conceito de linguagem e suas ramificações, condensando-se em um conhecimento único dentro do contexto amazônico e ao mesmo tempo corroborando no afloramento desse tema para futuras pesquisas em educação e ensino. Assim, selecionou-se alguns dos conceitos que emergiram das dissertações e teses analisadas. Das dissertações, extraímos os seguintes conceitos:

A construção do conhecimento científico tem a linguagem como um de seus elementos principais, pois ela é a ponte pra expressar o pensamento por meio da verbalização e da escrita, que na história da humanidade, vem depois da fala. (DUTRA, 2013, p. 18)

Afirmamos, com base nos estudos realizados, que cabe à Educação Infantil a função primordial de formar as bases para o desenvolvimento da linguagem escrita, entendendo que tais bases têm sua origem na capacidade de expressão das crianças, que deve ser o cerne de todo o trabalho educativo na escola dos pequenos (MORAES, 2013, p. 224).

Quanto ao desenvolvimento da linguagem oral das crianças da turma pesquisada, percebemos que o maior estímulo comunicativo que tinham na creche era o diálogo que procuravam manter entre si, fosse nos momentos das brincadeiras, das disputas e de espera. Outro ponto que observamos foi que quando as professoras buscavam manter um diálogo com as crianças, elas se empenhavam ao máximo para dar continuidade à conversa, embora tenhamos percebido que eram as crianças que tomavam a iniciativa em estabelecer um diálogo com as professoras [...] Além disso, o conhecimento e a valorização da cultura, dos costumes e hábitos, da linguagem das famílias e da comunidade são essenciais para um trabalho pedagógico pautado na compreensão das especificidades das crianças concretas e pronto a enriquecer suas formas de inserção social e de compreensão do mundo, das pessoas e de si mesmas (PINHO, 2013, p. 108).

[...] o diálogo exerce uma importância essencial, no processo de aprendizagem, pois o educador não lida só com a realidade objetiva, mas o universo de significados de uma realidade, que é de maneira simbólica estruturada, por meio dos signos, da linguagem, dos significados sociais atribuídos nas interações sociais, é que a aprendizagem se desenvolve (WURLER, 2017, p. 154).

Aprendemos ainda que o diálogo precisa ser um princípio educativo pressuposto em todas as relações propriamente humanas, pois, nós os humanos somos seres de/na linguagem. O diálogo cria reciprocidade e respeito pela alteridade. As relações mediadas pelo diálogo tendem a ser experiência de entendimento, de compreensão, de abertura, de comunicação, de criação de consenso, de libertação, de espontaneidade (como no jogo), de aprendizado prazeroso, de autonomia (SILVA NETO, 2018, p. 124-125).

A compreensão de que a linguagem é a ferramenta principal da comunicação entre os seres humanos e que a aprendizagem da linguagem científica insere os alunos numa cultura científica, necessária para a cidadania crítica, torna-se uma questão prioritária na Educação em Ciências (SANTOS, 2016, p. 94). 
Os seis conceitos que emergiram das dissertações dos mestrados acadêmico e profissional coincidem com os dizeres de Chomsky (2009, p. 12) ao afirmar que "a linguagem é o espelho da mente em um sentido profundo e significativo.” Para esse autor, a linguagem é "um produto da inteligência humana, criado de acordo com uma operação que está muito além do alcance da vontade ou da consciência" (ibid., p. 12).

E para fortalecer esse diálogo, é importante descrever o conceito de linguagem também encontrado nas teses:

Defender o desenho como linguagem da criança é a mensagem desta pesquisa. Entender o processo pelo qual a criança se apropria dessa linguagem e as mudanças que ela gera em seu desenvolvimento psíquico é discussão que desejamos continuar fazendo (PRINTES, 2018, p. 260).

\begin{abstract}
A linguagem matemática é constituída em geral de léxicos efetivamente especiais usados nas estruturas gramaticais e sintáticas linguísticas utilizadas por determinada comunidade matemática. Por outro lado, na produção de mensagens, as palavras existem nas situações em que elas são usadas. $O$ entendimento não é de um reconhecimento na existência de signos, mas na construção do sentido no contexto em que ele aparece. Sendo assim, o significado para uma proposição matemática tem sua origem numa realização da ação (performativo e pragmático) (LACERDA, 2017, p. 184).

Pensando mais diretamente em nosso objeto de estudo, destacamos que se faz necessário que a professora de bebês e crianças pequenininhas tenha consciência da importância do seu trabalho para o desenvolvimento da linguagem e do pensamento dos pequenos; que compreenda a influência da linguagem para todas as funções psíquicas da criança; que tenha conhecimento dos resultados do domínio da linguagem; e saiba que, por sua mediação a fala em si pode ser transformada em fala para si e para os outros (NOGUEIRA, 2016, p. 265).
\end{abstract}

Os conceitos de linguagem que emergiram das teses também produzidas nos programas de pós-graduação na região amazônica vão de encontro com os pensadores Chomsky e Maturana. Para Chomsky "o estudo da linguagem cai naturalmente nos limites da biologia humana". Ele afirma que:

\begin{abstract}
A faculdade da linguagem, que evoluiu de alguma forma na pré-história humana, ao mesmo tempo que inevitavelmente impõe limites aos tipos de linguagem capazes de ser adquiridos de maneira natural. Interagindo com outras faculdades da mente, torna possível o uso coerente e criativo de uma língua em termos que às vezes podemos descrever, mas temos dificuldade até mesmo para começar a entender (CHOMSKY, 2009, p. 119).
\end{abstract}

As palavras de Chomsky são reforçadas por Maturana ao afirmar que se pode abstrair desse conjunto de circunstâncias que está na linguagem o seguinte: 
A linguagem é um operar em coordenações em coordenações de ação. Não é meramente coordenação, mas coordenação de coordenações de ação, estão no espaço da reflexão. A linguagem como fenômeno consiste no operar em coordenações consensuais de comportamentos de coordenações consensuais de comportamentos (MATURANA, 2001, p. 70).

O autor chama nossa atenção utilizando os termos "coordenações" e "comportamentos de coordenações consensuais" para ilustrar o que se estabelece como "resultado de estar junto em interações recorrentes". E ele ainda acrescenta que as interações ou as coordenações consensuais de condutas "não são instintivas". Maturana (2001, p. 71) explica que "a diferença entre instinto ou comportamento instintivo e a conduta aprendida está na história" e para ele, não é possível distinguir, na conduta, uma conduta instintiva de uma aprendida porque distinção pertence à história. Em suma, é válido repetir o que resume o autor, ao dizer que "o central da linguagem são as coordenações de ação como resultado de interações recorrentes".

Em relação às categorias sobre a linguagem, conforme distribuição no gráfico 2, a mais recorrente foi Linguagem Matemática/Científica com 13 ocorrências, seguido por uma ordem decrescente representada com os quantitativos de 7,6 e 5 ocorrências, respectivamente, as seguintes categorias: Processo Cognitivo, Linguagem Oral e Escrita e a linguagem enquanto Dimensão Social. Com duas (2) ocorrências estão representadas as categorias: Linguística, Linguagem e Artes e linguagem como Gênero Textual. E com apenas uma única ocorrência foram identificadas as categorias: Gramática e Linguagem Gestual/Libras.

Gráfico 2 - Apresentação das categorias compiladas na RS.

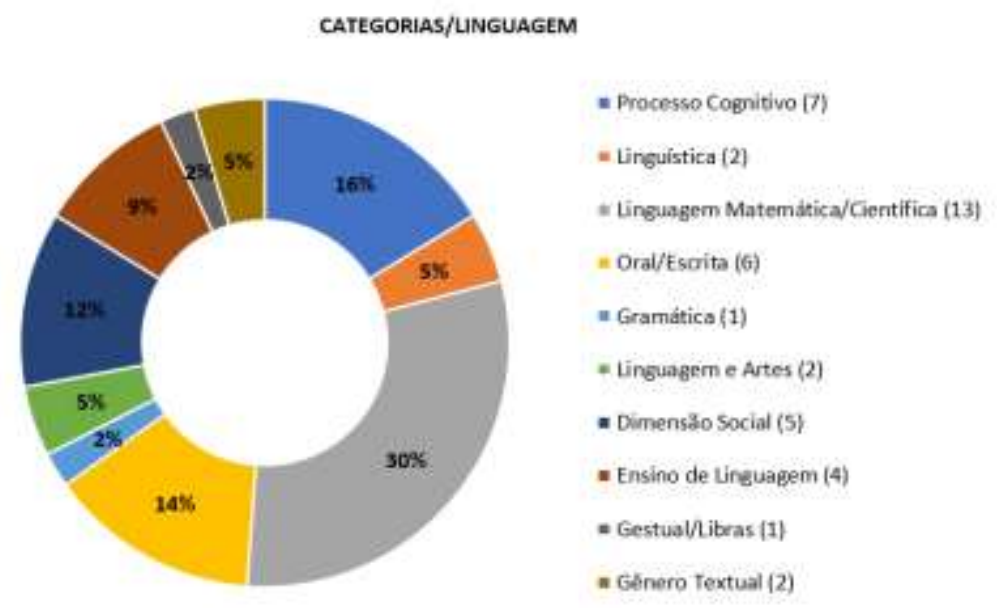

Fonte: elaborado pelos autores.

Os pesquisadores Santos (2016, p. 56) fundamentados em Oliveira (2009) afirmam que a linguagem científica propicia 
[...] o desenvolvimento do pensamento científico e com a complexificação deste pensamento, essa mesma linguagem científica se desenvolve, permitindo seu domínio pelo aluno. Por sua vez, esse domínio transforma-se num valioso instrumento de desenvolvimento dos processos cognitivos e os orienta para a construção do conhecimento.

Os estudos de Chomsky (2009, p. 57) chamam nossa atenção quando diz que em geral, as estruturas cognitivas são construídas conforme a pessoa vai amadurecendo, interagindo com a gramática e oferecendo condições para o uso da linguagem.

E em se tratando da linguagem, destaca-se que, a princípio, o objetivo era ler apenas o resumo, dado a condição do tempo, já que o título e as palavras-chave direcionariam as produções com a temática em evidência, o que não ocorreu. A estrutura da escrita dos resumos não possibilitou a identificação dos elementos elencados no protocolo de busca. Já, em relação aos resumos das produções acadêmicas, Megid Neto (1999) faz um alerta que todo pesquisador deveria conhecer suas palavras, bem como deveria considerar as observações por ele feita, ao exercitar a escrita na construção de outros resumos. Ele afirma que:

\begin{abstract}
Os resumos ampliam um pouco mais as informações disponíveis, porém, por serem muito sucintos e, em muitos casos, mal elaborados ou equivocados, não são suficientes para a divulgação dos resultados e das possíveis contribuições dessa produção para a melhoria do sistema educacional. Somente com a leitura completa ou parcial do texto final da tese ou dissertação desses aspectos (resultados, subsídios, sugestões metodológicas etc.) podem ser percebidos (MEGID NETO, 1999, p.45).
\end{abstract}

Em conformidade com o que nos alertou o autor, foi necessário ler além do Resumo, a Introdução, Fundamentação e Metodologia para que se pudesse consolidar com o proposto nos objetivos desta pesquisa.

Em seguida, convida-se o leitor a visualizar o quantitativo de produções científicas sobre a linguagem, distribuída por Estado que compõe a região amazônica, obedecendo à ordem alfabética, tais como: Acre, Amazonas, Amapá, Maranhão, Mato Grosso, Pará, Rondônia, Roraima e Tocantins, embora, no gráfico, os estados apareçam associados pelo quantitativo de textos encontrados no Banco de tese da Capes, de onde se destaca com maior expressividade os programas de pós-graduação localizados nos estados no Pará com 16 ocorrências e Mato Grosso com 15. 
Gráfico 3 - Quantitativo de produções sobre a linguagem por estado

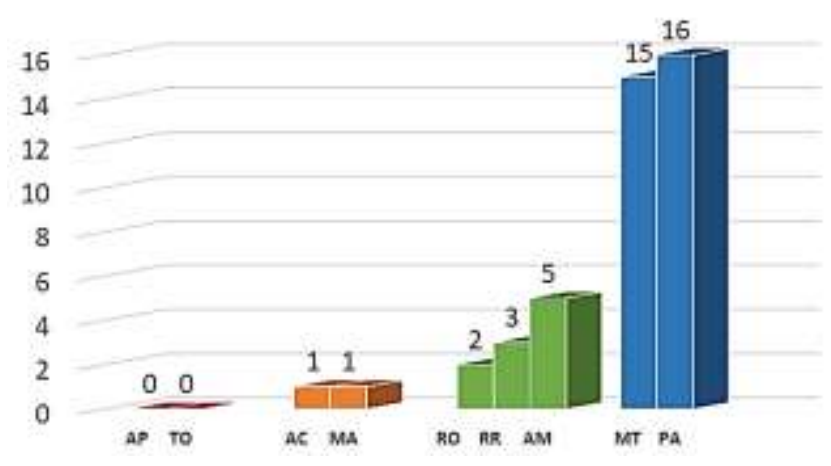

Fonte: elaborado pelos autores

Por uma questão de identificação geográfica em que se localizam, trabalham, estudam e pesquisam os referidos autores deste artigo, ilustra-se, aqui, os estados do Amazonas e Roraima, respectivamente, com 5 e 3 ocorrências.

No Acre e no Maranhão detectou-se apenas um trabalho em cada estado e no Amapá e Tocantins nenhum registro foi localizado, lembrando que a pesquisa limitou-se apenas aos anos de 2013 a 2018.

Considerando um dos principais filtros de busca da pesquisa, a saber, a educação e o ensino, área do conhecimento de maior concentração nos programas de pós-graduação, em especial da região amazônica, nosso estudo aponta que a string "linguagem" associado ao termo "educação" sobressai em relação ao quantitativo da produção na área do ensino, em que foi contabilizado, das 44 produções científicas analisadas, 25 refere-se a programas de pósgraduação em educação, cerca de $61 \%$, e 19 a programas de pós-graduação na área do ensino, como se observa no gráfico 4 .

Gráfico 4 - Relação da RS compiladas por área do conhecimento

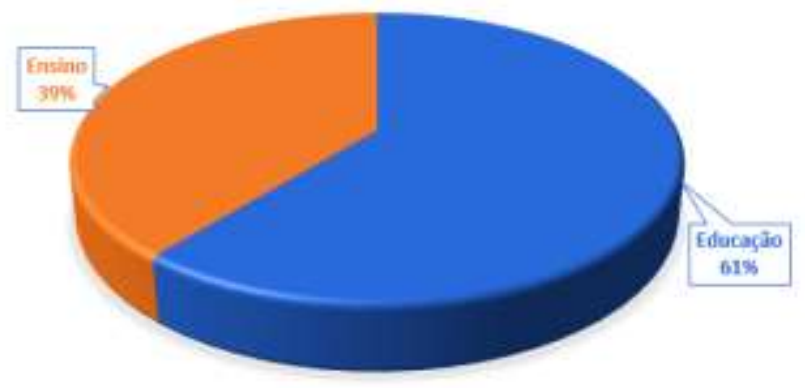

Fonte: elaborado pelos autores

É importante ressaltar, conforme os dados aqui expostos, a RS expõe uma limitada produção dos programas de pós-graduação em educação e ensino sobre a linguagem, 
demonstrando, dentro das limitações desta pesquisa, uma produção menor que $0,1 \%$ das pesquisas desenvolvidas em todo o país (Quadro 2) sobre a temática. É real e emergente a necessidade de construir uma representatividade teórico-metodológico ao estudo sobre linguagem, seja de qual natureza pertencer, valorizar, principalmente, aqueles que são desenvolvidos dentro do contexto único que é a região amazônica. Assim, com tais evidências, espera-se instigar novos pesquisadores na tarefa de contribuir, significativamente, ao estudo da linguagem no cenário amazônico.

\section{CONSIDERAÇÕES FINAIS}

Este trabalho serviu para sintetizar e sistematizar os estudos sobre a linguagem nas produções acadêmicas científicas dos programas de pós-graduação da região Amazônica em Educação e Ensino, bem como norteará o desenvolvimento de projetos de pesquisas nesta região.

É importante dizer que a realização de pesquisa por meio de Revisão Sistemática demanda tempo para as leituras e reflexões, requer do pesquisador habilidades não só para a análise e interpretação dos dados, bem como familiaridade com a tecnologia, em especial, com o uso do software STArt e o Wordle ${ }^{\mathrm{TM}}$.

Dado o rigor e o tempo destinado para a realização deste trabalho, foi tomada a decisão de realizar um levantamento das teses e dissertações, no Banco de Dados da Capes, para composição de uma revisão sistemática sobre o estudo da linguagem nos programas de pósgraduação, em educação e ensino, da região amazônica objetivando conhecer as produções existentes, além de conhecer o caminho metodológico percorrido por tais pesquisadores, a fim de despertar interesse em pesquisadores a trilhar por caminhos retos em futuras pesquisas científicas ou aprofundamento, seja de mestrados ou doutorados.

Sabe-se que o tema linguagem, apesar de parecer simples, pelo fato de ser um vocábulo presente no cotidiano, quando se trata de teor científico, as complexidades surgem e como nos lembra Chomsky não é tão simples entender a "linguagem como o espelho da mente."

Por outro lado, foi muito compensador, saber que na região Amazônica, a linguagem já comparece nas pesquisas, em várias categorias, mas as que chamam atenção entre todas, foram as produções que apontaram a linguagem científica e o processo cognitivo, por essas categorias ancorarem possibilidades de desenvolvimento de projeto de pesquisa no âmbito do doutorado na região amazônica, especificamente em programas listados nesta pesquisa. 
A realização desta pesquisa tomada por caminho o banco de tese Capes para consulta em resumos na realização da leitura para categorização dos dados tem salientado limites, dado o critério posto na elaboração do protocolo. É bom explicitar para o pesquisador da região Norte, o limite também se centra no grande entrave com a internet e a queda de energia, além das condições do próprio site da Capes.

Diante do exposto, comunga-se das ideias de Medig Neto (1999), as quais são reforçadas por André (2001), ao revelar que a variação no formato de apresentação dos resumos das dissertações e teses é um dos fatores que dificultam a análise, pois alguns resumos são muito sucintos e outros confusos ou incompletos, sem informação sobre o tipo de pesquisa e os procedimentos de coleta de dados.

Em suma, é importante destacar que os resultados deste estudo não são suficientes para esgotar todas as questões ligadas e interligadas à linguagem, seja na educação ou no ensino. E por esta razão, declara-se que, fazer este levantamento de dados, durante o mês de maio do corrente ano, despertou o interesse em aprofundar outros e mais estudos sobre a linguagem, a partir do que foi estruturado para esta revisão sistemática, pela questão norteadora: Como a linguagem é discutida nas teses e dissertações dos programas de pós-graduação, em educação e ensino, da região amazônica? E assim, espera que outras perspectivas e expectativas venham contribuir na formação continuada de professores, em especial, da região Amazônica.

\section{REFERÊNCIAS}

ALVES, T. S. Cartografia Linguística da Cidade de Marapanim/PA: uma análise semântico lexical no contexto educacional amazônico. 2013. 1041 f. Dissertação (Mestrado em Educação), Programa de Pós-Graduação em Educação da Universidade do Estado do Pará, Belém, 2013. Disponível em: https://sucupira.capes.gov.br/sucupira/public/consultas/coleta/trabalhoConclusao/viewTrabalh oConclusao.jsf?popup=true\&id trabalho=656439. Acesso em: 08 de março de 2019.

ANDRÉ, Marli Eliza Dalmazo Afonso de. A pesquisa sobre formação de professores no Brasil - 1990-1998. In: CANDAU, Vera M. (Org.). Ensinar e aprender: sujeitos, saberes e pesquisa. 2.ed. Rio de Janeiro: DP\&A, 2001.

CHOMSKY, Noam. Reflexões sobre a linguagem. Tradução Mário Leite Fernandes. 1. ${ }^{\mathrm{a}}$ ed. São Paulo: JSN Editora, 2009.

DUTRA, A. C. M. A Contribuição do vídeo como linguagem no ensino-aprendizagem de conceitos científicos no $9^{\circ}$ ano do ensino fundamental. 2013. 77f. Dissertação (Mestrado Acadêmico em Educação em Ciências na Amazônia), Universidade do Estado do Amazonas, Programa de Pós-Graduação em Educação e Ensino de Ciências na Amazônia, Manaus, 2013. Disponível em: http://www.pos.uea.edu.br/data/area/titulado/download/38-3.pdf. Acesso em: 08 de março de 2019. 
GONZÁLEZ REY, Fernando Luis. Pesquisa Qualitativa e Subjetividade: os processos de construção da informação. Tradução Marcel Aristides Ferrada Silva. São Paulo: Cengage Learning, 2015.

LACERDA, A. G. As práticas didático-pedagógicas no ensino e aprendizagem de conceitos matemáticos: horizontes reconstrutivos aos processos de formação, leitura e comunicação. 2017. 197 f. Tese (Doutorado em Educação em Ciências e Matemática), Universidade de Mato Grosso, Pós-Graduação em Educação em Ciências e Matemática (PPGECEM) da Rede Amazônica de Educação em Ciências e Matemática (REAMEC), Cuiabá, 2017. Disponível em: https://sucupira.capes.gov.br/sucupira/public/consultas/coleta/trabalhoConclusao/viewTrabalh oConclusao.jsf?popup=true\&id trabalho=5393732. Acesso em: 07 de março de 2019.

MATURANA, Humberto. Cognição, ciência e vida cotidiana. Organização e tradução Cristina Magro, Victor Paredes. - Belo Horizonte: Ed. UFMG, 2001.

MEGID NETO, Jorge. Tendências da pesquisa acadêmica sobre o ensino de ciências no nível fundamental. 1999. 114 f. Tese (Doutorado em Educação) - Universidade Estadual de Campinas, Faculdade de Educação, Campinas, São Paulo, 1999. Disponível em: http://repositorio.unicamp.br/handle/REPOSIP/252565. Acesso em: 10 de março de 2019.

MORAES, A. J. A. B. A atividade pedagógica do professor e o processo de apropriação da linguagem escrita pela criança pré-escolar: um estudo a partir da abordagem históricocultural. 2015. 241 f. Dissertação (Mestrado em Educação) - Universidade Federal do Amazonas, Programa de Pós-graduação em Educação, Manaus, 2015. Disponível em: https://sucupira.capes.gov.br/sucupira/public/consultas/coleta/trabalhoConclusao/viewTrabalh oConclusao.jsf?popup=true\&id_trabalho=2795391. Acesso em: 10 de março de 2019.

NOGUEIRA, A. A. Interações e desenvolvimento da linguagem oral em crianças na creche: uma abordagem histórico-cultural. 2016. 294 f. Tese (Doutorado em Educação) Universidade Federal do Amazonas, Programa de Pós-graduação em Educação, Manaus, 2016. Disponível em: https://sucupira.capes.gov.br/sucupira/public/consultas/coleta/trabalhoConclusao/viewTrabalh oConclusao.jsf?popup=true\&id_trabalho=3637577. Acesso em: 12 de março de 2019.

PINHO, E. M. R. O que você fala, professor, tem importância? O trabalho pedagógico na creche e o desenvolvimento da linguagem oral da criança. 2013. 131 f. Dissertação (Mestrado em Educação) - Universidade Federal do Amazonas, Manaus, 2013. Disponível em: https://sucupira.capes.gov.br/sucupira/public/consultas/coleta/trabalhoConclusao/viewTrabalh oConclusao.jsf?popup=true\&id_trabalho=1199906. Acesso em: 12 de março de 2019.

PRINTES, J. S. O desenho da Educação Infantil: Perspectivas de formação de professores a partir da teoria Histórico Cultural. 2018. 287 f. Tese (Doutorado em Educação) Universidade Federal do Amazonas, Programa de Pós-graduação em Educação, Manaus, 2018. Disponível em: https://tede.ufam.edu.br/handle/tede/6500. Acesso em: 15 de março de 2019.

ROMANOWSKI, Joana Paulin; ENS, Romilda Teodora. As pesquisas denominadas do tipo "Estado da Arte" em Educação. Diálogo Educ., Curitiba, v. 6, n.19, p.37-50, set./dez, 2006. Disponível em: https://periodicos.pucpr.br/index.php/dialogoeducacional/article/view/24176> Acesso em: 03 de março de 2019. 
SÁ, T. R. Pelos caminhos da cartografia linguística paraense: um estudo semântico-lexical do Distrito Mosqueiro numa perspectiva socioeducacional. 2013. 282f. Dissertação (Mestrado em Educação) - Universidade do Estado do Pará, Programa de Pós-Graduação em Educação, Belém, 2013. Disponível em: https://sucupira.capes.gov.br/sucupira/public/consultas/coleta/trabalhoConclusao/viewTrabalh oConclusao.jsf?popup=true\&id_trabalho=1229686. Acesso em: 10 de março de 2019.

SANTOS, M. S. O ensino e aprendizagem da ciência no ensino médio, à luz das compreensões da linguagem em Wittgenstein, Vigotsky e Gardner. 2016. 109 f. Dissertação (Mestrado Profissional em Ensino de Ciências da) - Universidade Estadual de Roraima, Programa de Pós-Graduação em Ensino de Ciências, Boa Vista, 2016. Disponível em: https://sucupira.capes.gov.br/sucupira/public/consultas/coleta/trabalhoConclusao/viewTrabalh oConclusao.jsf?popup=true\&id_trabalho=4323173. Acesso em: 13 de março de 2019.

SILVA NETO, F. B. Uma concepção de educação a partir do diálogo em Gadamer e Freire. 132 f. Dissertação (Mestrado em Educação) - Universidade do Estado do Pará, Belém, 2018. Disponível em: https://sucupira.capes.gov.br/sucupira/public/consultas/coleta/trabalhoConclusao/viewTrabalh oConclusao.jsf?popup=true\&id trabalho=2684456. Acesso em: 11 de março de 2019.

TRIVIÑOS, AUGUSTO Nibaldo Silva. Introdução à pesquisa em ciências sociais: a pesquisa qualitativa em educação. São Paulo: Atlas, 1987.

WURLER, D. Diálogo e Linguagem: subsídios teóricos de Paulo Freire e Lev Vygotski para a aprendizagem dialógica. 2017. 163 f. Dissertação (Mestrado em Educação) Universidade Federal de Mato Grosso, Programa de Pós-graduação em Educação, Rondonópolis, $2017 . \quad$ Disponível em: https://sucupira.capes.gov.br/sucupira/public/consultas/coleta/trabalhoConclusao/viewTrabalh oConclusao.jsf?popup=true\&id_trabalho=5163464. Acesso em 12 de março de 2019.

Submetido em: 17 de maio de 2020 .

Aprovado em: 03 de julho de 2020. 